Check for updates

Cite this: RSC Adv., 2017, 7, 22722

\title{
Synthesis of nanocrystallized zirconium carbide based on an aqueous solution-derived precursor
}

Received 2nd March 2017 Accepted 19th April 2017

DOI: 10.1039/c7ra02586f

rsc.li/rsc-advances

\author{
Jing-Xiao Wang, ${ }^{\text {abc }}$ De-Wei Ni, (D) *bc Shao-Ming Dong, ${ }^{\text {bc }}$ Guang Yang, ${ }^{a}$ \\ Yan-Feng Gao, (D) a Yan-Mei Kan, ${ }^{\text {bc }}$ Xiao-Wu Chen, ${ }^{\text {bc }}$ Yan-Peng Cao ${ }^{\text {abc }}$ \\ and Xiang-Yu Zhang*bc
}

Nanocrystallized zirconium carbide $(\mathrm{ZrC})$ powder was synthesized by an aqueous solution-based process using zirconium acetate and sucrose as starting reagents. Polyvinyl pyrrolidone (PVP) was used to combine the reactants to form a suitable precursor for $\mathrm{ZrC}$. Through such a novel aqueous solutionbased process, fine-scale mixing of the reactants is achieved in an environmentally friendly manner. The formed precursor can be converted to $\mathrm{ZrC}$ by carbothermal reduction reaction at $1600-1650{ }^{\circ} \mathrm{C}$. Thanks to a limited amount of residual free carbon, the as-synthesized $\mathrm{ZrC}$ powder had an ultra-fine particle size $(50-100 \mathrm{~nm})$ and a low oxygen content less than $1.0 \mathrm{wt} \%$. The conversion mechanisms from assynthesized pre-ceramic precursor to ZrC powder were investigated systematically and revealed by means of FTIR, TG-DSC, XRD, Raman, SEM and TEM.

\section{Introduction}

Zirconium carbide ( $\mathrm{ZrC})$ has been considered as a strategic material in many applications, such as field emitters, a coating for nuclear reactor particle fuels, and cutting tools etc., because of its outstanding properties (high melting point, high elastic modulus and hardness, and small neutron absorption crosssection etc.). ${ }^{1-3}$ However, due to its strong covalent bonding nature and low self-diffusion coefficient, ZrC shows very poor sinterability, which limits its applications. It has been widely realized that smaller particles can lower the sintering temperature and facilitate densification processes due to the larger surface area and higher reactivity of the smaller particles. ${ }^{4-6}$

Conventionally, $\mathrm{ZrC}$ is synthesized by solid state reactions between carbon and $\mathrm{Zr}, \mathrm{ZrH}_{2}$, or $\mathrm{ZrO}_{2}$. In many cases, high temperatures are required for the carbide-forming reactions because the powders are mixed together on a relatively coarse scale, e.g., micrometer-scale, which also leads to metal carbide products with relatively large particle sizes. ${ }^{7}$ Studies have also shown that ZrC can be synthesized by using precursors via solution-based processing methods. This becomes increasingly popular due to the advantages of homogenous distribution of all reactants at molecular level, which can lower the reaction

${ }^{a}$ School of Materials Science and Engineering, Shanghai University, Shanghai 200444, China

${ }^{b}$ State Key Laboratory of High Performance Ceramics and Superfine Microstructure, Shanghai Institute of Ceramics, Chinese Academy of Sciences, Shanghai 200050, China. E-mail: deweini@mail.sic.ac.cn; xyzhang@mail.sic.ac.cn; Fax: +86 21 69906085; Tel: +862169906033

${ }^{c}$ Structural Ceramics and Composites Engineering Research Center, Shanghai Institute of Ceramics, Chinese Academy of Sciences, Shanghai 200050, China temperature and shorten the reaction time, thus leading to fine particle size. Sacks et al. synthesized nano ZrC powders $(\sim 50-$ $130 \mathrm{~nm}$ ) using mixed solutions of zirconium $n$-propoxide $/ n$ propanol (as a zirconia source) and either phenolic resin or glycerol (as a carbon source). ${ }^{8}$ Investigation by Yan et al. revealed that carbon sources and various ligands chelation showed a remarkable influence on morphology and particle size of the synthesized ZrC powders. ${ }^{9-11}$ With an additional foaming process, Li et al. synthesized $\mathrm{ZrC}$ nanopowder $(175 \mathrm{~nm})$ using zirconium oxychloride octahydrate and sucrose as $\mathrm{Zr}$ and $\mathrm{C}$ sources respectively. ${ }^{12}$

In most of the reported cases for ZrC synthesis by solutionbased processing, organic reactants and organic solvent were usually used, which is expensive, complex and not environmentally friendly. In this work, ZrC was synthesized by carbothermal reduction via an aqueous solution-derived precursor, in which zirconium acetate and sucrose were used as $\mathrm{Zr}$ and $\mathrm{C}$ sources respectively. Polyvinyl pyrrolidone (PVP) was used to combine the reactants to form a proper precursor for $\mathrm{ZrC}$. The conversion mechanisms from as-synthesized pre-ceramic precursor to ZrC powder were investigated in detail. As well, the effect of residual free carbon on the synthesized ZrC was investigated.

\section{Experimental procedures}

\subsection{Materials and processing}

Zirconium acetate $\left(\mathrm{ZrO}\left(\mathrm{CH}_{3} \mathrm{COO}\right)_{2}\right.$, purity 99\%, Yixing Xinxing Zirconium Co., Ltd, Yixing, China), sucrose $\left(\mathrm{C}_{12} \mathrm{H}_{22} \mathrm{O}_{11}\right.$, AR grade, Aladdin industrial Corporation, Shanghai, China), and polyvinyl pyrrolidone (PVP, Beijing HWRK Chem Co., Ltd, 
Beijing, China) were used as starting materials. According to reaction $\mathrm{ZrO}_{2}+3 \mathrm{C}=\mathrm{ZrC}+2 \mathrm{CO}(\mathrm{g})$, molar ratio between $\mathrm{ZrO}\left(\mathrm{CH}_{3} \mathrm{COO}\right)_{2}$ and $\mathrm{C}_{12} \mathrm{H}_{22} \mathrm{O}_{11}$ was adjusted in a range of $4: 1$ to $4: 1.5$. The PVP addition was controlled at around $2 \mathrm{wt} \%$ in the precursor solution. The starting materials were mixed with deionized water under constant stirring for $24 \mathrm{~h}$ to form a uniform aqueous solution-derived precursor.

The obtained precursor was cross-linked and cured at $85{ }^{\circ} \mathrm{C}$ for $12 \mathrm{~h}$ in drying oven. And then it was pyrolyzed at $600{ }^{\circ} \mathrm{C}$ for $2 \mathrm{~h}$ under flowing argon atmosphere with a heating rate of $1^{\circ} \mathrm{C}$ $\min ^{-1}$. The pyrolyzed precursor was subsequently heat treated at $1400-1650{ }^{\circ} \mathrm{C}$ for $2 \mathrm{~h}$ in vacuum for carbothermal reduction with a heating rate of $5{ }^{\circ} \mathrm{C} \mathrm{min}^{-1}$. The as-obtained products after carbothermal reduction could be ground into fine powders easily for further characterization.

\subsection{Characterization}

Fourier transform infrared (FTIR) spectra of both the starting materials and precursors were measured by NICOLET Is 10 spectrometer (Thermo Fisher Scientific, Massachusetts, USA). Thermal gravimetric analysis (TG) and differential scanning calorimetry (DSC) were performed on a Netzsch STA 499 F3 Jupiter ${ }^{\circledR}$ in argon flow at a heating rate of $10{ }^{\circ} \mathrm{C} \mathrm{min}^{-1}$ over the range of $40-1400{ }^{\circ} \mathrm{C}$.

The morphologies of the as-synthesized powders were observed using a field emission scanning electron microscope (FESEM, Merlin Compact, Zeiss, Germany). As well, the characterizations of morphologies were performed using a $200 \mathrm{kV}$ transmission electron microscope (TEM, JEOL JEM-2100F, Japan) along with selected area electron diffraction (SAED). The particle size of the synthesized ZrC powder were determined by post processing of the SEM images, using freeware software Image ${ }^{\circledR}$. To reduce the error in the determination, at least ten images with hundreds of crystallites were taken in random regions of the samples and used for the statistical analysis. X-ray diffraction (XRD) patterns were collected on a Rigaku Ultima IV diffractometer with $\mathrm{Cu}$ target $(40 \mathrm{kV}, 40 \mathrm{~mA})$ over the angle range of $10-85^{\circ}$. The Rietveld refinement of the $\mathrm{XRD}$ profile was carried out to determine the influence of residual carbon on crystal structure of the as-synthesized powder. Raman spectroscopy (Thermo Nicolet, USA) was also carried out for the synthesised powders. The oxygen content of the as-synthesized ZrC powder was determined by a nitrogen/ oxygen determinator (TC600, LECO, St. Joseph, MI). The carbon content of the as-synthesized powders was detected by chemical analysis.

\section{Results and discussion}

Using $\mathrm{ZrO}\left(\mathrm{CH}_{3} \mathrm{COO}\right)_{2}$ and $\mathrm{C}_{12} \mathrm{H}_{22} \mathrm{O}_{11}$ as starting reagents, PVP was used to combine the reactants to form the precursor for ZrC. Infrared spectroscopy was used to investigate the structural evolution and principal interactions of the precursor during heat treatment (Fig. 1). The FTIR spectra of the starting materials are also shown here for comparison. The respective assignments of the absorption peaks are $3440(v(\mathrm{O}-\mathrm{H})+$

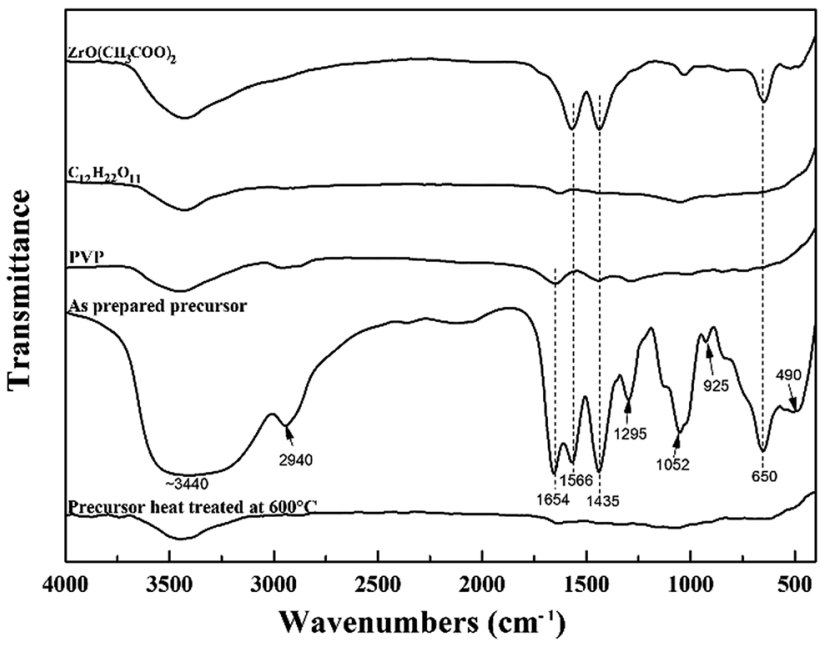

Fig. 1 FTIR spectra of the starting materials and precursors.

$\left.v\left(\mathrm{NH}_{2}\right)\right), 2940(v(\mathrm{C}-\mathrm{H})), 1654(v(\mathrm{C}=\mathrm{O})), 1566(v(\mathrm{C}=\mathrm{O})), 1435$ $(v(\mathrm{C}=\mathrm{O})+\delta(\mathrm{CH})), 1295\left(\delta(\mathrm{C}-\mathrm{H})+v\left(\mathrm{C}-\mathrm{CH}_{3}\right)\right), 1052(v(\mathrm{OOC})), 925$ $\left(v\left(\mathrm{C}-\mathrm{CH}_{3}\right)+v(\mathrm{C}=\mathrm{O})\right)$, and $650\left(\pi\left(\mathrm{C}-\mathrm{CH}_{3}\right)+v(\mathrm{Zr}-\mathrm{O})+\right.$ ring distortion $)$ and $400-500(v(\mathrm{Zr}-\mathrm{O})) \mathrm{cm}^{-1} \cdot{ }^{13}$ For the precursor after cross-linking and curing at $85{ }^{\circ} \mathrm{C}$, the broad peak at $3440 \mathrm{~cm}^{-1}$ assigned to $v(\mathrm{O}-\mathrm{H})$ and $v\left(\mathrm{NH}_{2}\right)$ is attributed to the stretching vibration of $-\mathrm{NH}_{2}$ and $-\mathrm{OH}$ groups. It shifts to lower wavenumber, indicating $-\mathrm{NH}_{2}$ and $-\mathrm{OH}$ groups take part in the complexation reaction. The peak at $1654 \mathrm{~cm}^{-1}$ from FTIR spectra of PVP is assigned to $v(\mathrm{C}=\mathrm{O})$, which is easily chelated to zirconium, thus largely reducing the tendency of zirconium to form bulk gels. Furthermore, the peaks at around 3400 and $1650 \mathrm{~cm}^{-1}$ of the precursor prior to pyrolysis are strong indication of the presence of absorbed water, which is also confirmed in the following discussion on DSC and TG results. The two peaks located at $650,490 \mathrm{~cm}^{-1}$, which are attributed ring distortion $+v(\mathrm{Zr}-\mathrm{O})$ of the cyclic structure after zirconium chelation and $v(\mathrm{Zr}-\mathrm{O})+v(\mathrm{Zr}-\mathrm{N})$, respectively, ${ }^{\mathbf{1 4}}$ appear in the FTIR curve of the precursor. This is very important for achievement of the homogeneous and intimate mixing of all the components for the followed carbothermal reduction reaction. After heat treatment at $600{ }^{\circ} \mathrm{C}$, almost all the absorption peaks disappear, indicating pyrolysis processes complete and nearly no residual organics exist.

The pyrolysis process of the precursor material was studied by simultaneous TG and DSC analysis, which are illustrated in Fig. 2. The pyrolysis processes of the precursor can be divided into four stages. Due to the evaporation of free water and separation of adsorbed water, there is a considerable weight loss occurring below $160{ }^{\circ} \mathrm{C}$, which results in an apparent endothermic peak on the DSC curve. The weight loss at this stage is around $12.23 \%$. Next, the second stage is located between 160 and $240{ }^{\circ} \mathrm{C}$, corresponding to the evaporation of constitution water and organic by products, where the weight loss is around $12.24 \%$. This is consistent with a shoulder endothermic peak on the DSC curve. Then, the third stage between 240 and $500{ }^{\circ} \mathrm{C}$ is attributed to the decomposition of 


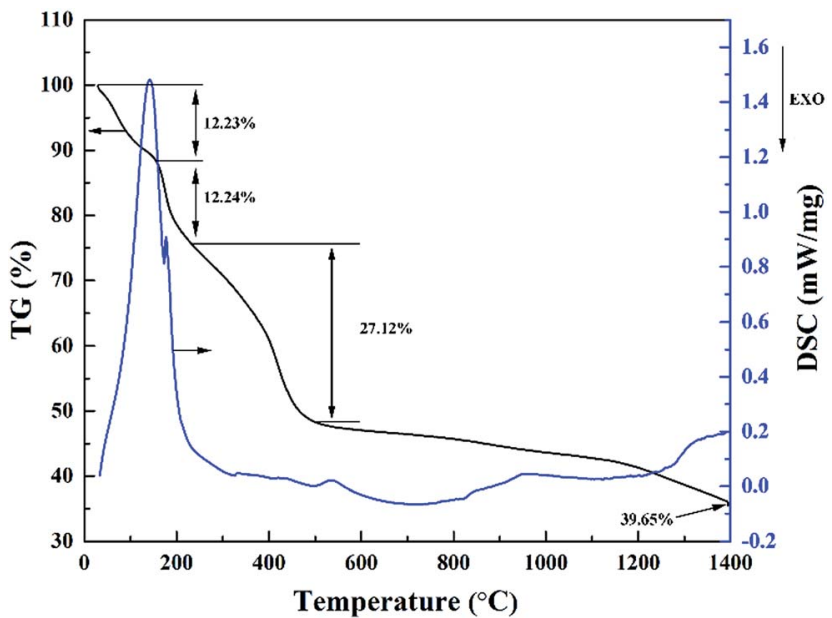

Fig. 2 TG-DSC curves of the as-obtained $\mathrm{ZrC}$ precursor dried at $85^{\circ} \mathrm{C}$.

$\mathrm{ZrO}\left(\mathrm{CH}_{3} \mathrm{COO}\right)_{2}, \mathrm{C}_{12} \mathrm{H}_{22} \mathrm{O}_{11}$ and PVP, leading to a weight loss of around $27.12 \%$. After $500{ }^{\circ} \mathrm{C}$, the weight loss tends to be very slow, where the TG curve is almost flat. This stage is probably corresponding to the continuous carbonization of sucrose and the transformation of $\mathrm{ZrO}_{2}$ crystalline phase. ${ }^{15,16}$ Subsequently, carbothermal reduction reaction started at temperature around $1400{ }^{\circ} \mathrm{C}$. Based on the above discussion of TG-DSC results, the pyrolysis temperature of the precursor is settled at $600{ }^{\circ} \mathrm{C}$ to reduce the volatile components, and the carbothermal reduction temperature is set to be $1400-1600{ }^{\circ} \mathrm{C}$. Based on TG analysis of individual raw materials (not shown here), a molar ratio of $4: 1.5$ for $\mathrm{ZrO}\left(\mathrm{CH}_{3} \mathrm{COO}\right)_{2}: \mathrm{C}_{12} \mathrm{H}_{22} \mathrm{O}_{11}$ was first used in the precursor according to carbothermal reduction reaction $\mathrm{ZrO}_{2}+$ $3 \mathrm{C}=\mathrm{ZrC}+2 \mathrm{CO}(\mathrm{g})$.

XRD was used to study the conversion of phase composition during heat treatment. Fig. 3 shows the XRD patterns of $\mathrm{ZrC}$ precursor after heat treatment at temperatures from 1400 to

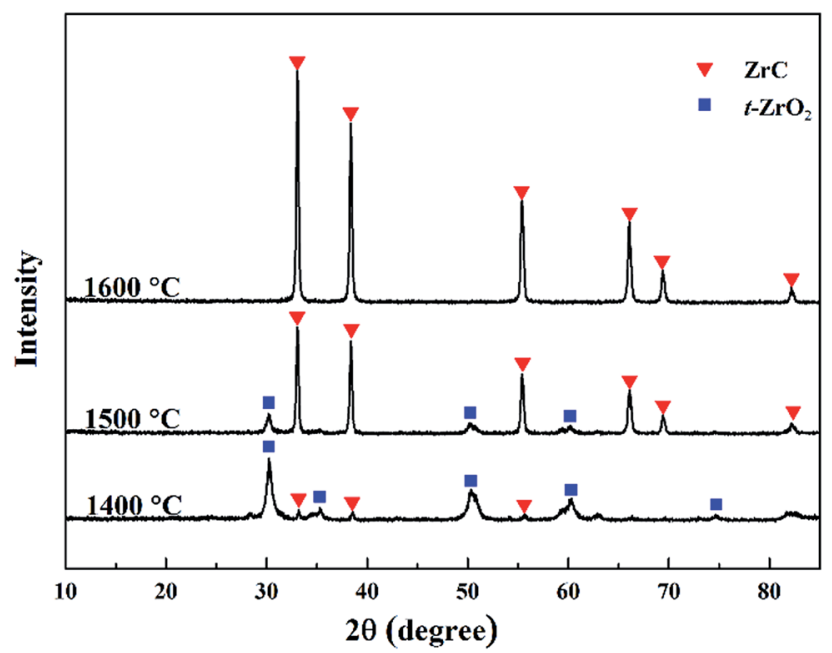

Fig. 3 XRD patterns of the $\mathrm{ZrC}$ precursor $\left(\mathrm{ZrO}\left(\mathrm{CH}_{3} \mathrm{COO}\right)_{2}: \mathrm{C}_{12} \mathrm{H}_{22} \mathrm{O}_{11}\right.$ $=4: 1.5)$ after heat treatment at temperatures from 1400 to $1600{ }^{\circ} \mathrm{C}$.
$1600{ }^{\circ} \mathrm{C}$, where the molar ratio of $\mathrm{ZrO}\left(\mathrm{CH}_{3} \mathrm{COO}\right)_{2}: \mathrm{C}_{12} \mathrm{H}_{22} \mathrm{O}_{11}$ was $4: 1.5$ in the precursor. After heat treatment at $1400^{\circ} \mathrm{C}$, the initial formation of $\mathrm{ZrC}$ is observed in the sample but $\mathrm{t}-\mathrm{ZrO}_{2}$ is the predominant phase. This result is in good agreement with the TG analysis discussed above. As well, it was observed that the vacuum degree of the furnace chamber started to decrease at about $1350{ }^{\circ} \mathrm{C}$, which was a sign of the carbothermal reduction reaction beginning. On the other hand, it is well known that tetragonal phase of zirconia can be stabilized to room temperature by carbon and tiny particle size. ${ }^{17,18}$ Therefore, it's $t-\mathrm{ZrO}_{2}$ rather than $\mathrm{m}-\mathrm{ZrO}_{2}$ observed in the sample. $\mathrm{ZrC}$ becomes the predominant phase in the sample heat treated at $1500{ }^{\circ} \mathrm{C}$, but small amount of $t-\mathrm{ZrO}_{2}$ still existed. After heat treatment at $1600{ }^{\circ} \mathrm{C}$, pure $\mathrm{ZrC}$ can be detected and no evidence of $\mathrm{ZrO}_{2}$ is observed on the XRD pattern. However, measurement indicated that oxygen content of the as synthesized $\mathrm{ZrC}$ powder at $1600^{\circ} \mathrm{C}$ is as high as $1.27 \mathrm{wt} \%$. Therefore, a further heat treatment at a higher temperature $\left(1650^{\circ} \mathrm{C}\right)$ had been carried out, where the oxygen content was reduced to $1.0 \mathrm{wt} \%$.

SEM images of the as-synthesized $\mathrm{ZrC}$ powders are presented in Fig. 4. It is clear that there are two completely different morphologies in both powders. In addition to the equiaxial $\mathrm{ZrC}$ particles with some extent of agglomeration, a flocculent material also presents surrounding the $\mathrm{ZrC}$ particles. EDS analysis (not shown here) indicates that the flocculent material is residual carbon. Chemical analysis shows that the residual free carbon in the $\mathrm{ZrC}$ powder synthesized at $1600{ }^{\circ} \mathrm{C}$ is around $3.7 \mathrm{wt} \%$. Compared with the $\mathrm{ZrC}$ powder synthesized at $1600^{\circ} \mathrm{C}$, less residual carbon $(1.4 \mathrm{wt} \%)$ is achieved at $1650{ }^{\circ} \mathrm{C}$, as also shown in Fig. 4. Particle size of the $\mathrm{ZrC}$ powders are mainly distributed in the range of $50-100 \mathrm{~nm}$ with a mean size of $56 \mathrm{~nm}$, which is much smaller than $\mathrm{ZrC}$ powders synthesized through traditional solid state reactions or sol-gel methods. ${ }^{19,20}$ No evident particle coarsening is observed at the higher temperature $\left(1650^{\circ} \mathrm{C}\right)$. It is known that grain growth is mostly determined by mass transfer and mainly occurs among particles via surface diffusion. ${ }^{21}$ Previously, it has been reported that carbon black could limit $\mathrm{HfO}_{2}$ growth by physically separating the oxide particles. ${ }^{22}$ Thus, it is believed that the existence of the residual carbon in this work reduces the particle mutual contact, thus preventing the particle coarsening and leading to ultra-fine particle size.

To further investigate the effect of residual free carbon on the synthesized $\mathrm{ZrC}$ powders, $\mathrm{ZrC}$ powders from precursors with different ratio of $\mathrm{ZrO}\left(\mathrm{CH}_{3} \mathrm{COO}\right)_{2}: \mathrm{C}_{12} \mathrm{H}_{22} \mathrm{O}_{11}$ were prepared. Corresponding Rietveld refinement for XRD patterns of the synthesized $\mathrm{ZrC}$ powders are shown in Fig. $5 . \mathrm{ZrC}$ is the only phase detected for all the three $\mathrm{ZrC}$ powders which is nicely refined using cubic $F m \overline{3} m$ space group in the region of $10-85$ degrees. According to the Rietveld refinement, lattice parameter of the cubic $\mathrm{ZrC}$ phase was calculated, which is $4.6595 \AA, 4.6872$ $\AA$ and $4.6880 \AA$, respectively.

It has been reported in literature that non-stoichiometric $\mathrm{ZrC}_{1-x}$ could be formed in the $\mathrm{Zr}-\mathrm{C}$ binary system. ${ }^{23,24}$ However, it was thought in the present case that the residual carbon would react with $\mathrm{ZrC}$ lattice to form non-stoichiometric $\mathrm{Zr}_{1-x} \mathrm{C}$ according to the following reaction: 

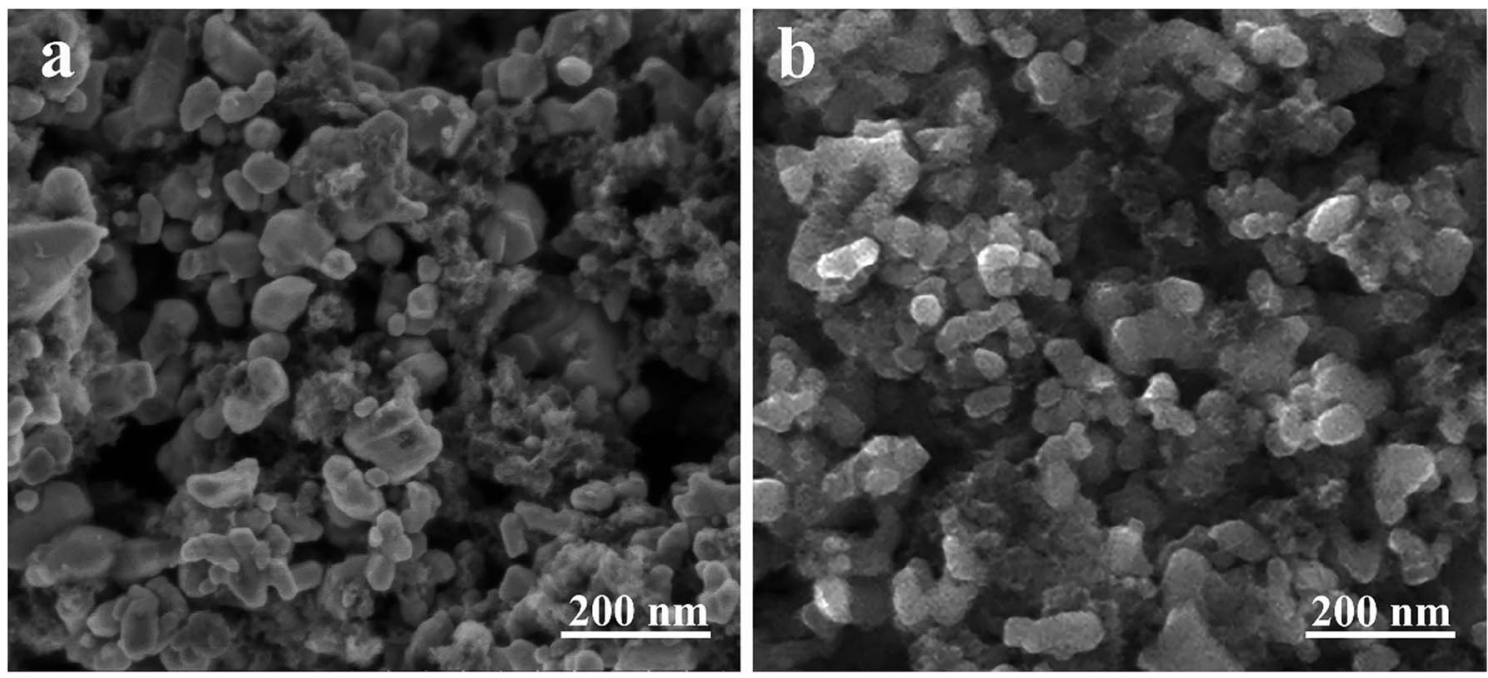

Fig. 4 SEM images of $\operatorname{ZrC}$ powders obtained at (a) $1600^{\circ} \mathrm{C}$ and (b) $1650{ }^{\circ} \mathrm{C}$.

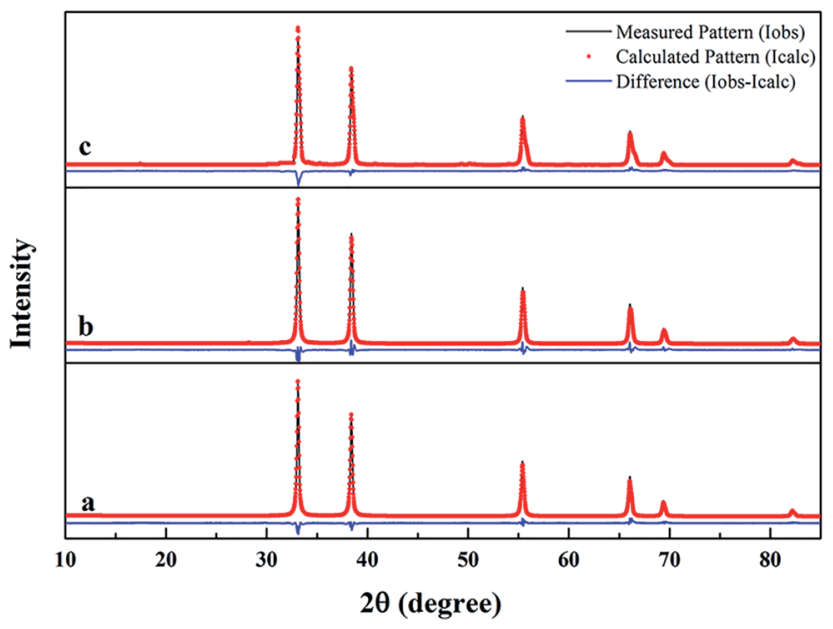

Fig. 5 Rietveld refinement for XRD patterns of synthesized $\mathrm{ZrC}$ powders from precursors with different ratio of $\mathrm{ZrO}\left(\mathrm{CH}_{3} \mathrm{COO}\right)_{2}$ $\mathrm{C}_{12} \mathrm{H}_{22} \mathrm{O}_{11}$ : (a) $4: 1.5$; (b) $4: 1.2$; (c) $4: 1$.

$$
(1-x) \mathrm{ZrC}+x \mathrm{C} \rightarrow \mathrm{Zr}_{1-x} \mathrm{C}
$$

The lattice parameter a of stoichiometric ZrC has been reported to be $4.693 \AA$ (PDF\#350784). The decrease in lattice parameter of $\mathrm{ZrC}$ phase in this work implies the formation of non-stoichiometric $\mathrm{Zr}_{1-x} \mathrm{C}$ according to the above reaction. As the increase of residual free carbon ( $x$ value), more $\mathrm{Zr}$ vacancies/ non-stoichiometric $\mathrm{Zr}_{1-x} \mathrm{C}$ could be formed, leading to smaller lattice parameter. Furthermore, vacancies/non-stoichiometry also results in microstrains in the lattice, which is 0.441 , $0.341,0.158$, respectively, as indicated by the Rietveld refinement results of XRD.

Chemical analysis indicates that the contents of residual free carbon in the synthesized ZrC powders are around $1.4 \mathrm{wt} \%, 0.8$ $\mathrm{wt} \%$ and $0.5 \mathrm{wt} \%$ respectively. Raman spectra of the synthesized ZrC powders are shown in Fig. 6. Two typical peaks centered at $\sim 1330$ and $\sim 1590 \mathrm{~cm}^{-1}$ are detected in all the three samples, corresponding to the $\mathrm{D}$ and $\mathrm{G}$ peaks of free carbon, revealing the presence of residual free carbon in the powders. ${ }^{25}$ Moreover, the intensity of $\mathrm{D}$ and $\mathrm{G}$ peaks decrease significantly with the increase of $\mathrm{ZrO}\left(\mathrm{CH}_{3} \mathrm{COO}\right)_{2}: \mathrm{C}_{12} \mathrm{H}_{22} \mathrm{O}_{11}$ ratio, indicating the decrease of residual carbon in the powders. This is in good agreement with the chemical analysis.

Fig. 7 exhibits the TEM and HRTEM images of synthesized ZrC powders from precursors with different ratio of $\mathrm{ZrO}\left(\mathrm{CH}_{3}\right.$ $\mathrm{COO})_{2}: \mathrm{C}_{12} \mathrm{H}_{22} \mathrm{O}_{11}$. SAED images (insets in Fig. 7a-c) reveal that the equiaxial particles are cubic $\mathrm{ZrC}$. It can be found that the three powders show similar morphology with comparable particle size ( $56 \mathrm{~nm}, 60 \mathrm{~nm}$ and $61 \mathrm{~nm}$ respectively). With the decrease of $\mathrm{C}_{12} \mathrm{H}_{22} \mathrm{O}_{11}$ in the starting materials, the content of amorphous free carbon decreases remarkably, showing good agreement with the chemical analysis discussed above. It appears that a limited amount $(0.5 \mathrm{wt} \%)$ of residual free carbon is enough in preventing grain coarsening of ZrC. Further

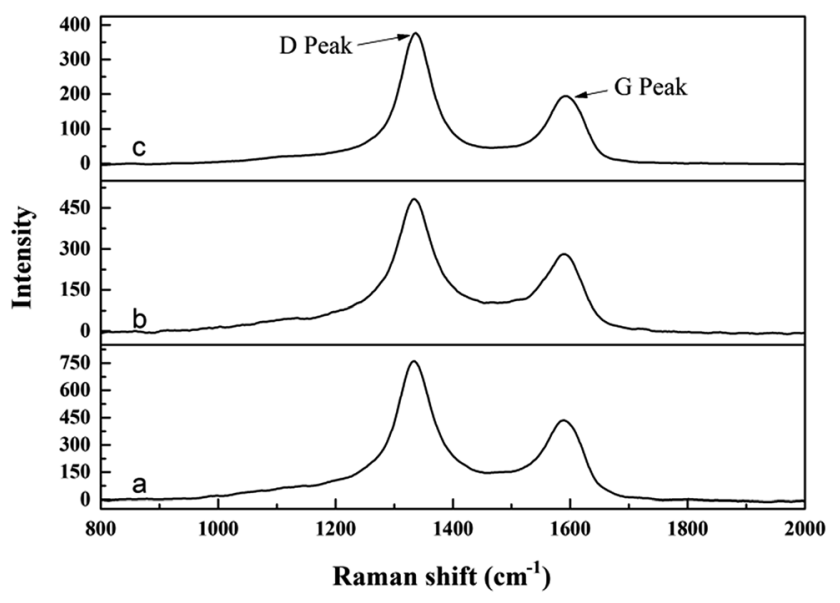

Fig. 6 Raman spectra of synthesized $\mathrm{ZrC}$ powders from precursors with different ratio of $\mathrm{ZrO}\left(\mathrm{CH}_{3} \mathrm{COO}\right)_{2}: \mathrm{C}_{12} \mathrm{H}_{22} \mathrm{O}_{11}$ : (a) 4 : 1.5; (b) 4 : 1.2; (c) $4: 1$. 

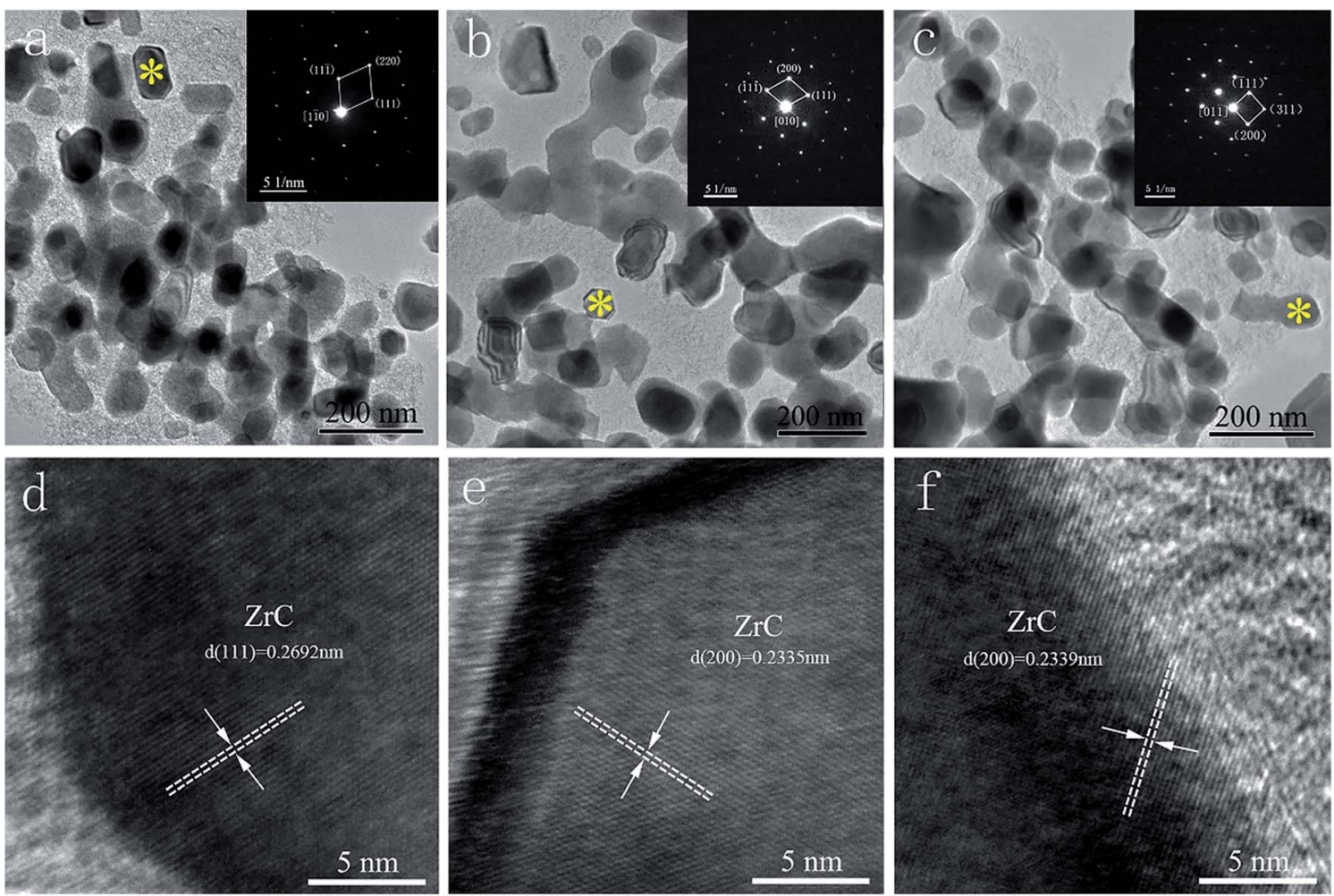

Fig. 7 TEM and HRTEM images of synthesized $\mathrm{ZrC}$ powders from precursors with different ratio of $\mathrm{ZrO}\left(\mathrm{CH}_{3} \mathrm{COO}\right)_{2}: \mathrm{C}_{12} \mathrm{H}_{22} \mathrm{O}_{11}:(\mathrm{a}$ and d) $4: 1.5$; (b and e) $4: 1.2$; ( $c$ and f) $4: 1$. The selected area electron diffraction (SAED) patterns of ZrC particles are inserted in (a), (b) and (c) at the * position respectively.

decrease of $\mathrm{C}_{12} \mathrm{H}_{22} \mathrm{O}_{11}$ in the starting materials can lead to serious grain coarsening or $\mathrm{ZrO}_{2}$ impurity. As can be seen in the HRTEM images (Fig. 7d-f), the particles have lattice fringes with the interlayer distance of $0.23-0.27 \mathrm{~nm}$ (as indicated in the images), which corresponds to the (200) or (111) planes of ZrC crystal. The calculated lattice parameter based on the lattice fringes show very good consistent with the values from XRD results. This further confirms the formation of nonstoichiometric $\mathrm{Zr}_{1-x} \mathrm{C}$ in the synthesized $\mathrm{ZrC}$ powders. It is believed that the non-stoichiometric $\mathrm{Zr}_{1-x} \mathrm{C}$ powders with nano size would be beneficial for the subsequent sinter and densification of the materials. ${ }^{23}$

\section{Conclusions}

Nanocrystallized ZrC powders were synthesized by an environmentally friendly aqueous solution-based processing using zirconium acetate and sucrose, combined with polyvinyl pyrrolidone (PVP) to form a precursor for $\mathrm{ZrC}$ with high stability. The precursor can be transformed into cubic $\mathrm{ZrC}$ by carbothermal reduction reaction at $1600-1650{ }^{\circ} \mathrm{C}$. It is revealed that the limited amount of residual free carbon can react with $\mathrm{ZrC}$ and lead to the formation of non-stoichiometric $\mathrm{Zr}_{1-x} \mathrm{C}$. Furthermore, the limited amount $(\sim 0.5 \mathrm{wt} \%)$ of residual free carbon can also reduce the mutual contact of $\mathrm{ZrC}$ particles and prevents the particle coarsening, leading to the ultra-fine particle size $(\sim 50-100 \mathrm{~nm})$ in the synthesized $\mathrm{ZrC}$ powders. It is believed that the non-stoichiometric $\mathrm{Zr}_{1-x} \mathrm{C}$ powders with ultra-fine particle size would be beneficial for the subsequent densification of the materials.

\section{Acknowledgements}

The financial support from the "The National Key Research and Development Program of China" (No. 2016YFB070020X), Chinese Academy of Sciences Innovative Funding (CXJJ-17-M169), "CAS Pioneer Hundred Talents Program" and Shanghai Key Projects of Basic Research (Grant No. 14JC1406200) are greatly acknowledged.

\section{References}

1 K. Minato, T. Ogawa, K. Sawa, A. Ishikawa, T. Tomita, S. Iida and H. Sekino, Nucl. Technol., 2000, 130, 272-281.

2 H. O. Pierson, Handbook of refractory carbides and nitrides: Properties, characteristics, processing and applications, Noyes Publication, New York, NY, United States, 1997.

3 X. Zhang, Q. Qu, J. Han, W. Han and C. Hong, Scr. Mater., 2008, 59, 753-756.

4 R. Chaim, M. Levin, A. Shlayer and C. Estournès, Adv. Appl. Ceram., 2013, 107, 159-169.

5 X. Kuang, G. Carotenuto and L. Nicolais, Adv. Perform. Mater., 1997, 4, 257-274.

6 M. J. Mayo, Int. Mater. Rev., 1996, 41, 85-115.

7 M. Zhang, Q. Hu, B. Huang and J. Li, J. Alloys Compd., 2011, 509, 8120-8125. 
8 M. D. Sacks, C.-A. Wang, Z. Yang and A. Jain, J. Mater. Sci., 2004, 39, 6057-6066.

9 C. Xie, M. Chen, X. Wei, M. Ge and W. Zhang, J. Am. Ceram. Soc., 2012, 95, 866-869.

10 C. Yan, R. Liu, Y. Cao, C. Zhang and D. Zhang, J. Sol-Gel Sci. Technol., 2012, 64, 251-256.

11 C. Yan, R. Liu, Y. Cao, C. Zhang and D. Zhang, Ceram. Int., 2013, 39, 3409-3412.

12 F. Li, X. Huang and G.-J. Zhang, Ceram. Int., 2015, 41, 33353338.

13 H. Y. Liu, X. Q. Hou, X. Q. Wang, Y. L. Wang, D. Xu, C. Wang, W. Du, M. K. Lü and D. R. Yuan, J. Am. Ceram. Soc., 2004, 87, 2237-2241.

14 X. Tao, W. Qiu, H. Li and T. Zhao, Polym. Adv. Technol., 2010, 21, 300-304.

15 Z. Dong, X. Zhang, Q. Huang, J. Zhang, X. Zuo, W. Li, G. Yuan and X. Li, Ceram. Int., 2015, 41, 7359-7365.

16 F. Li, M. Liang, X.-F. Ma, X. Huang and G.-J. Zhang, J. Porous Mater., 2015, 22, 493-500.
17 Y. Li, C. Tian, L. Zhao, Y. Li, S. Jin and S. Li, J. Chin. Ceram. Soc., 2009, 37, 1273-1276.

18 R. C. Garvie and M. F. Goss, J. Mater. Sci., 1986, 21, 12531257.

19 M. Dolle, D. Gosset, C. Bogicevic, F. Karolak, D. Simeone and G. Baldinozzi, J. Eur. Ceram. Soc., 2007, 27, 2061-2067.

20 C. Yan, R. Liu, Y. Cao, C. Zhang and D. Zhang, J. Am. Ceram. Soc., 2012, 95, 3366-3369.

21 D.-W. Ni, J.-X. Liu and G.-J. Zhang, J. Eur. Ceram. Soc., 2012, 32, 2557-2563.

22 J. X. Liu, Y. M. Kan and G. J. Zhang, J. Am. Ceram. Soc., 2010, 93, 980-986.

23 X.-G. Wang, W.-M. Guo, Y.-M. Kan, G.-J. Zhang and P.-L. Wang, J. Eur. Ceram. Soc., 2011, 31, 1103-1111.

24 O. M. Barabash and Y. N. Koval, Crystal Structure of Metals and Alloys, Kiew, Naukova Dumka, 1986, pp. 215-216, in Russian.

25 A. Sadezky, H. Muckenhuber, H. Grothe and R. Niessner, Carbon, 2005, 43, 1731-1742. 